https://www.journal-imab-bg.org

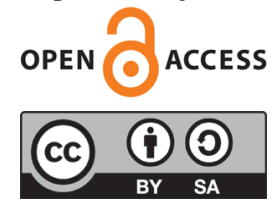

Case report

\title{
CORONALLY ADVANCED FLAP TECHNIQUE FOR ROOT COVERAGE IN THE AESTHETIC ZONE OF UPPER JAW
}

\author{
Irena Georgieva \\ Department of Periodontology and Dental Implantology, Faculty of Dental \\ Medicine, Medical University Varna, Bulgaria.
}

\begin{abstract}
:
Introduction: Different surgical techniques (pedicle and free soft-tissue grafting) are proposed for treatment of the exposed root surface in the aesthetic zone of dentition. A coronally advanced flap is a suitable technique that can be used for root coverage in treatment of gingival recessions of single tooth as well as multiple teeth. Two different techniques of the coronally advanced flap are proposed: trapezoidal flap and triangular flap. Clinicians tend to use a surgical approach which could be minimally invasive as possible. This can be achieved by periodontal microsurgical technique. Microsurgical instruments with suitable magnification devices and illumination would be predominantly proposed.

Purpose: The aim of this case report is to demonstrate the comparison in therapeutic outcome between coronally advanced flap technique with a microsurgical approach and coronally advanced flap technique with a conventional approach for root coverage in the aesthetic zone of upper jaw.

Material and methods: Miller's class I gingival recessions, affecting tooth 11 and tooth 12, are established. A microsurgical approach is used in the treatment of tooth 11 and conventional coronally advanced flap in case of tooth 12 .

Results: Complete root coverage and gain of clinical attachment level are achieved in both approaches.

Conclusion: This case report demonstrates similar results in both approaches - conventional and microsurgical ones.
\end{abstract}

Keywords: gingival recession, coronally advanced flap, microsurgery, clinical attachment gain, aesthetic zone,

\section{INTRODUCTION:}

Over the years different surgical techniques (pedicle and free soft-tissue grafting) are proposed for treatment of mucogingival defects of the exposed root surface in the aesthetic zone of dentition, where the expectations of the patient are very high.

A coronally advanced flap is a suitable technique that can be used for root coverage in cases of gingival re- cessions of single tooth_as well as multiple teeth. This technique shows good results in the treatment of class I Miller gingival recessions with adequate thickness and height of apical keratinized tissues to the exposed root surface. Different techniques of the coronally advanced flap (CAF) [1] are proposed by several authors in the years - Allen and Miller[2], Zuchelli and De Sanctis.[3]

There are two alternatives of the design of coronally advanced flap: trapezoidal flap and triangular flap. Zuchelli and De Sanctis proposed the trapezoidal CAF[3], and later Zuchelli et al. introduced a modified CAF with a triangular design which effectiveness is comparable to the trapezoidal CAF's one.[1] In case of the trapezoidal flap, the trapezoidal surgical papillae are placed over triangular recipient anatomical papillae, and as a result, there is an excess of soft tissue covering avascular tooth surface.[4]

In the treatment of exposed root surface, clinicians tend to use a surgical approach which could be minimally invasive as possible. This can be achieved by periodontal microsurgical technique. Microsurgical instruments with suitable magnification devices and illumination would be predominantly proposed.[5]

The aim of this case report is to demonstrate the comparison in therapeutic result between CAF technique with a microsurgical approach and CAF technique with conventional surgical approach for root coverage in the aesthetic zone of the maxilla.

\section{CS DESCRIPTION:}

The patient is 36 years old female, non-smoker, with no systemic diseases, and no medicaments intake. She complains of individual aesthetic disorder in right upper incisors region due to vestibular gingival recessions and complains of hypersensitivity in this area. No mobility of teeth in the aesthetic zone of the maxilla is reported.

Miller's class I gingival recessions, affecting tooth 11 and tooth 12, are established in the course of the clinical examination. Medical history and periodontal status (probing depth, recession depth, clinical attachment level (CAL), the height of keratinized gingiva) were recorded.

The depth of the gingival recession is $3 \mathrm{~mm}$ for tooth 11 and $2 \mathrm{~mm}$ for tooth 12 . 
Pic. 1. Preoperative view \#11

Pic. 2. Preoperative view \#12
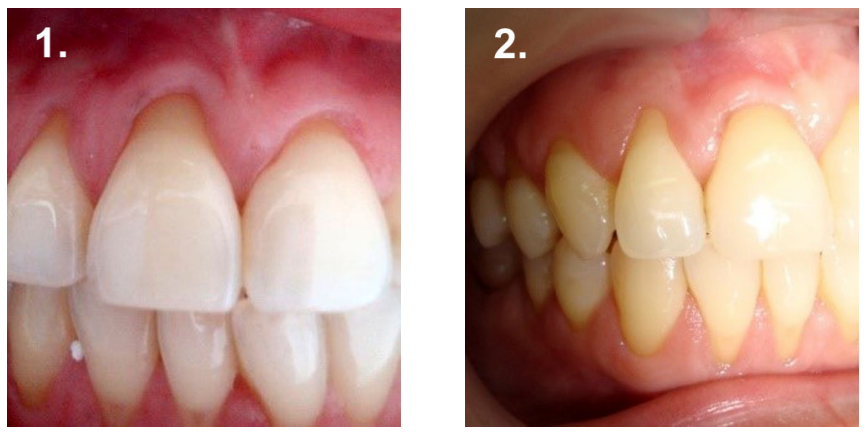

Informed consent form is signed by the patient. Scaling and polishing are performed 2 weeks before the surgical procedure.

Treatment: CAF and microsurgical approach in case of the maxillary right central incisor (\#11)

This surgical approach is performed using using surgical microscope, magnification $4 \mathrm{x}$, required illumination, microsurgical instruments and 6/0 Dafilon suture material.

The technique is introduced by two horizontal incisions in the zone of interdental papillae, being distant from the tip of the anatomical papillae, and equal to the height $(3 \mathrm{~mm})$ of the gingival recession. These horizontal incisions are coronally to the cemento-enamel junction (CEJ) at the mesial and distal line axis of the tooth and are followed by two apically divergent vertical releasing incisions, extending 3-4 $\mathrm{mm}$ apically into the alveolar lining mucosa. The releasing incisions facilitate displacement of the coronally advanced flap. A split-thickness flap is elevated mesially and distally to the recession by sharp dissection with a microblade held in parallel to the root surface and connected with an intracrevicular incision. A full-thickness flap is elevated apically to the receded soft tissue margin on the facial aspect of the root. This permits to preserve the entire thickness of gingival tissues, apically to the recession.

\section{Pic. 3. Elevation of flap}

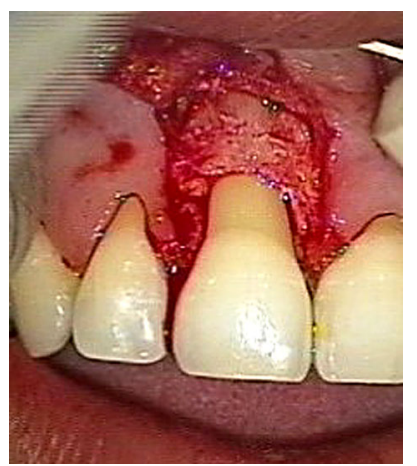

The full-thickness elevation is continued approximately $3 \mathrm{~mm}$ apically to the bone dehiscence, and then a horizontal incision is made through the periosteum to facilitate the displacement of the flap and reduce the muscle tension in time of suturing. A root planing of the exposed root surface is made, but the root surface in the zone near to the anatomical bone dehiscence must be avoided during root planning, due to damaging of the connective tissue fibers inserting into the cementum near the bone crest. The root planing is continued until a smooth, clean, and hard root surface is obtained. The facial portion of the interdental papillae is deepithelialized to allow the replacement of the flap margin coronally to the CEJ and suturing the surgical papilla to the connective tissue beds in the anatomical papilla regions. The surgical papillae are sutured to th5_deepithelialized anatomical ones with sling suture and interrupted $\mathrm{O}$-shaped sutures are applied in the zone of releasing incisions. The suture material that is used is non-absorbable monofilament 6/0 sutures (Dafilon).

Pic. 4. Suturing

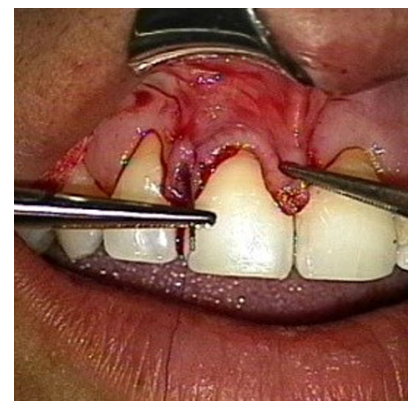

$0,12 \%$ chlorhexidine rinse solution was prescribed three times daily, and the patient was informed not to brush the surgical area until the surgical sutures are removed.

Pic. 5. Postoperatively

Pic. 6. 5 days after surgical manipulation
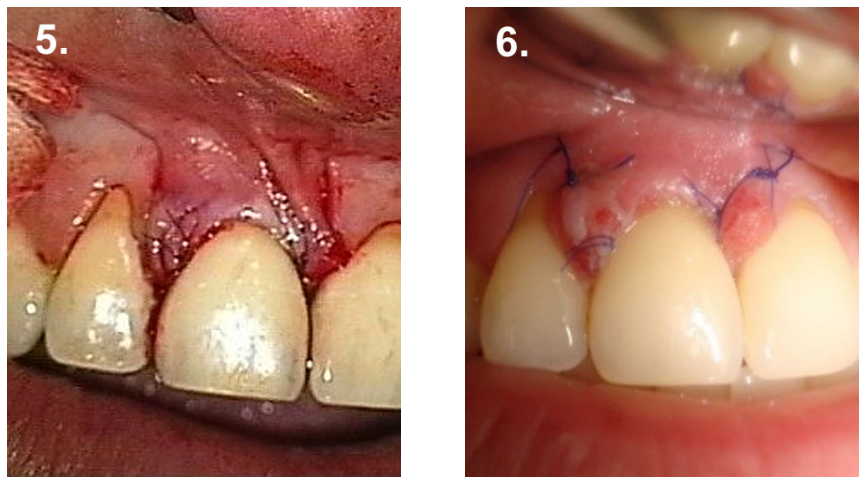

The patient was invited 8 days after the manipulation for sutures removal. Adequate therapeutic effect on the surgical wound is registered.

The microsurgical approach ensures better visibility of the surgical zone, good illumination and more precise incisions, suturing and elevation of flap due to the usage of microsurgical instruments. 
Pic.7. 8 days after (before sutur5s removal)

Pic. 8. 2 months after surgery
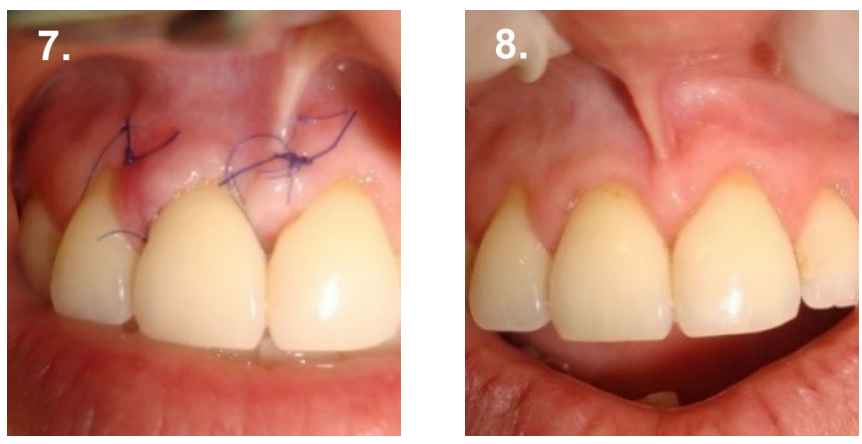

Pic. 9. Postoperative view

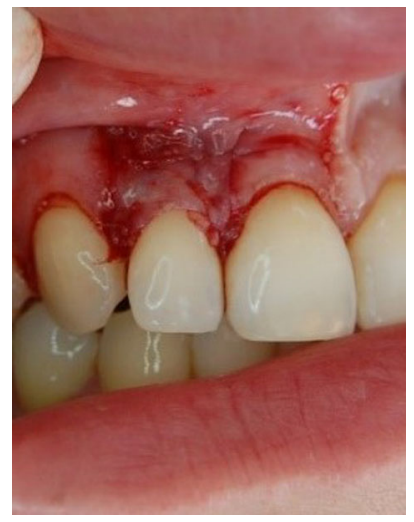

Pic. 10. Sutures removal

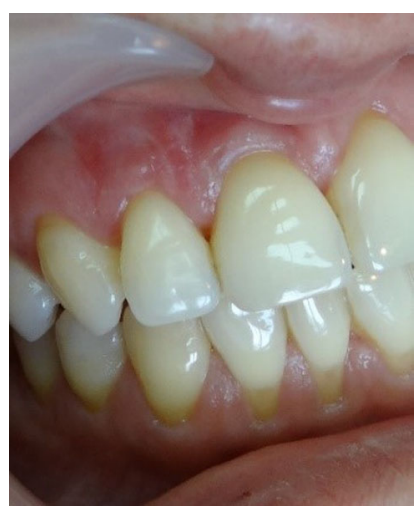

Complete root coverage and gain of CAL are achieved in both approaches: CAL gain is $3 \mathrm{~mm}$ in the case of central incisor\#11 and CAL gain is $2 \mathrm{~mm}$ in the case of lateral incisor\#12.

No scar formation is registered. Satisfying colour

Pic. 12. Preoperative clinical view

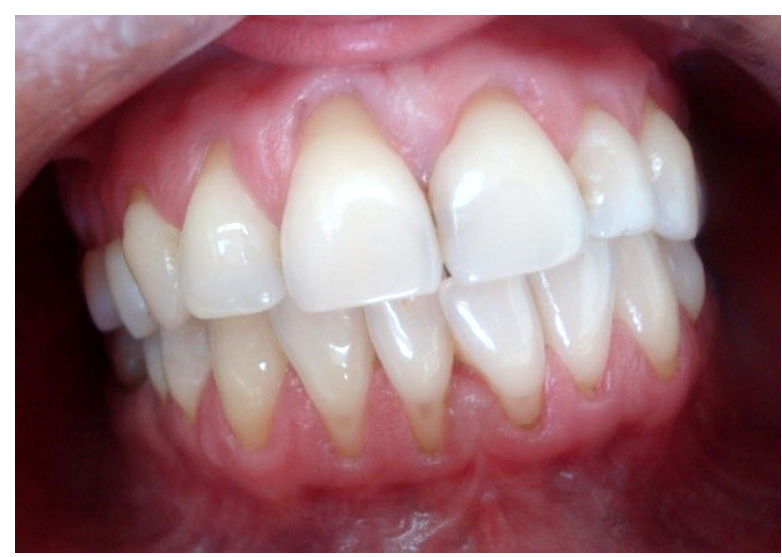

match is achieved.

The patient was satisfied with the esthetic result of

Conventional CAFapproachin case of the maxillary right lateral incisor (\#12)

Two months after the microsurgical approach, a conventional CAF technique was performed in the case of maxillary right lateral incisor (tooth 12). The surgical protocol that was used is the same as the technique mentioned above but without using magnification, illumination and microsurgical instruments.

Postoperative instructions were given. The patient was invited 7 days later, and the sutures were removed.

Pic. 11. 2 months postoperative clinical view (\#12)

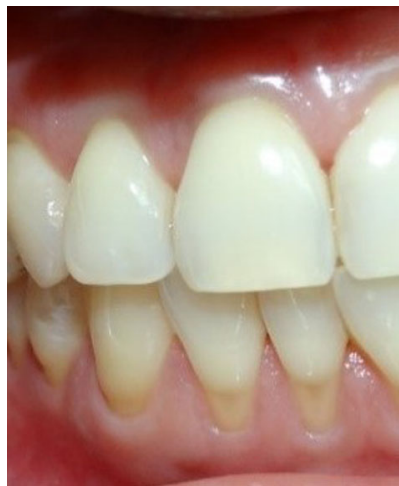
the manipulations and the sensitivity in the cervical zone, both incisors were reduced after the procedures.

The patient was followed-up, and the results are stable 4 years later.

Pic. 13. Postoperative clinical view (4 years after)

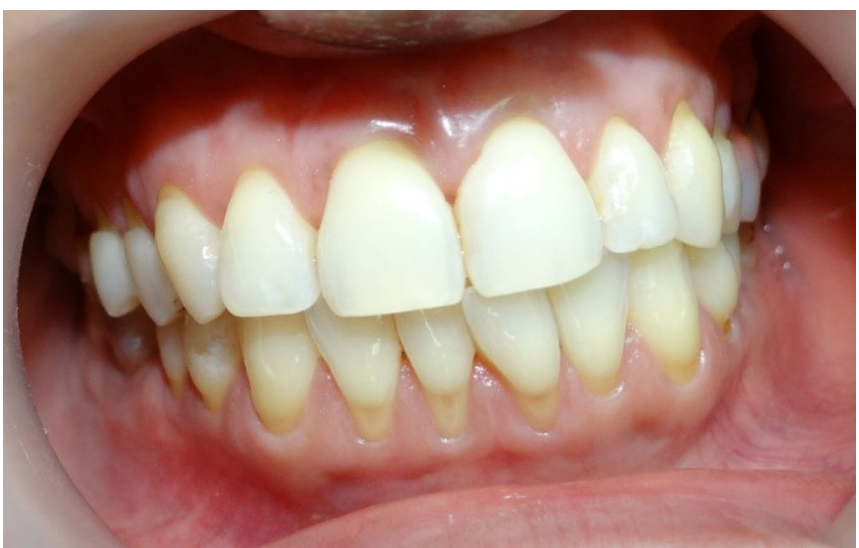




\section{DISCUSSION:}

Coronally advanced flap alone, or in combination with subepithelial connective tissue grafts, guided tissue regeneration (GTR) or other biomaterials are surgical techniques that can be used for root coverage in treatment of localized or multiple recession-type defects. [6] Various studies report about the efficacy of CAF alone in the treatment of localized facial gingival recessions with respect to recession reduction and complete root coverage. [7]

Another studies and reports demonstrate the comparison between microsurgical and conventional approach of trapezoidal CAF. [5, 8]

This case report shows similar results in respect to clinical attachment level gain and the width of keratinized gingiva between both approaches. We noted a gain of clinical attachment level and an increase in the width of the attached gingiva in both procedures.

There are different evidence about the efficiency of microsurgical periodontal instruments in surgical treatment for root coverage of the exposed root surface due to gingival recessions. [8]

The advantages of the microsurgical approach are magnification, illumination and increased precision and all they ensure minimal postoperative discomfort. But the microsurgical technique also has some disadvantages as the fact that it is a time-consuming and expensive approach.

\section{CONCLUSION:}

This case report demonstrates similar results in both approaches - conventional and microsurgical ones. We obtained a staisfying colour match and precise flap proximity with both techniques. But we can conclude that there is a better view control of the surgical field and more accuracy of surgery with a microsurgical approach.
ABBREVIATIONS:
CAF - coronally advanced flap
CAL - clinical attachment level
CEJ - cemento-namel junction
GTR - guided tissue regeneration

\section{REFERENCES:}

1. Zucchelli G, Stefanini M, Ganz S, Mazzotti C, Mounssif I, Marzadori $\mathrm{M}$, et al. Coronally advanced flap with different designs in the treatment of gingival recession: A Comparative controlled randomized clinical trial. Int $J$ Periodontics Restorative Dent. 2016 May-Jun;36(3):319-27 [PubMed]

2. Allen EP, Miller PD Jr. Coronal positioning of existing gingiva: Short term results in the treatment of shallow marginal tissue recession. J Periodontol. 1989 Jun;60(6):316-9. [PubMed]

3. De Sanctis M, Zucchelli G. Coronally advanced flap: A modified surgical approach for isolated recessiontype defects: Three-year results. J Clin
Periodontol. 2007 Mar;34(3):262-8 [PubMed]

4. Zucchelli G. (Quintessenza Edizioni) Mucogingival esthetic surgery. 2013, Chapter 17, p. 257-329

5. Francetti L, Del Fabbro M, Calace S, Testori T, Weinstein RL. Microsurgical treatment of gingival recession: A controlled clinical study. Int J Periodontics Restorative Dent. 2005 Apr;25(2):181-8 [PubMed]

6. Chambrone L, Salinas Ortega MA, Sukekava F, Rotundo R, Kalemaj $\mathrm{Z}$, Buti J, et al. Root coverage procedures for treating localised and multiple recession-type defects. Cochrane Database Syst Rev. 2018 Oct 2;10(10):CD007161. [PubMed]
[Crossref]

7. Cairo F, Nieri M, Pagliaro U. Efficacy of periodontal plastic surgery procedures in the treatment of localized facial gingival recessions. A systematic review. J Clin Periodontol. 2014 Apr; 41(Suppl 15):S44-62. [PubMed] [Crossref]

8. Andrade PF, Grisi MF, Marcaccini AM,Fernandes PG, Reino DM, Souza SL, et al. Comparison between micro- and macrosurgical techniques for the treatment of localized gingival recessions using coronally positioned flaps and enamel matrix derivative. J Periodontol. 2010 Nov;81(11):1572-9 [PubMed] [Crossref]

Please cite this article as: Georgieva I. Coronally advanced flap technique for root coverage in the aesthetic zone of upper jaw. J of IMAB. 2020 Jul-Sep;26(3):3267-3270. DOI: https://doi.org/10.5272/jimab.2020263.3267

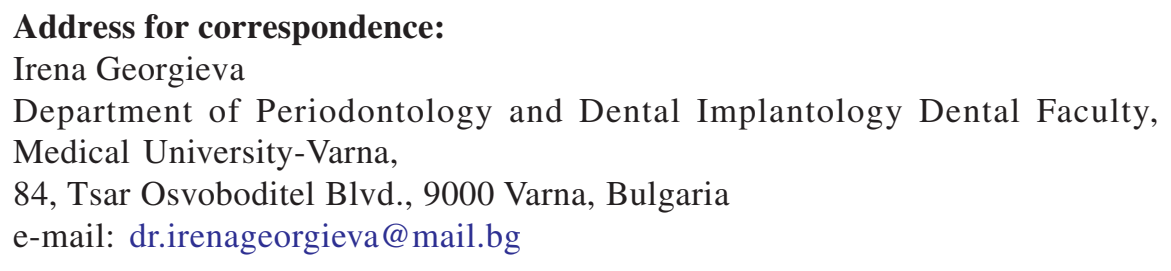

